\title{
Erratum to: Folate-Regulated Changes in Gene Expression in the Anterior Neural Tube of Folate Binding Protein-1 (Folbp1)-Deficient Murine Embryos
}

\author{
Ofer Spiegelstein • Robert M. Cabrera • \\ Daniel Bozinov • Bogdan Wlodarczyk • \\ Richard H. Finnell
}

Published online: 4 January 2014

(c) Springer Science+Business Media New York 2014

\section{Erratum to: Neurochem Res, 29(6), 1105-1112, 2004}

DOI 10.1023/B:NERE.0000023597.37698.13

The citation for Table 1 was present in the article published in 29(6), 1105-1112, 2004. However, the table was erroneously not published in the article.

The missing table is given below:

Special issue on Expression Profiling Within the Central Nervous System II.

The online version of the original article can be found under doi:10.1023/B:NERE.0000023597.37698.13.

O. Spiegelstein · R. M. Cabrera - D. Bozinov · B. Wlodarczyk ·

R. H. Finnell

Center for Environmental and Genetic Medicine, Institute of

Biosciences and Technology, Texas A\&M University System

Health Science Center, Houston, TX, USA

Present Address:

O. Spiegelstein

Teva Pharmacueticals, Petach Tivka, Israel

B. Wlodarczyk

National Veterinary Research Institute, Pulawy, Poland

R. H. Finnell $(\square)$

Center for Environmental and Genetic Medicine, Institute of Biosciences and Technology, Texas A\&M University System Health Science Center, 2121, W. Holcombe Boulevard.,

Houston, TX 77030, USA

e-mail: rfinnell@ibt.tmc.edu
Table 1 Enriched ontological clusters and their respective genes

\begin{tabular}{|c|c|c|c|}
\hline $\begin{array}{l}\text { Biological function } \\
\text { Gene name }\end{array}$ & $\begin{array}{l}\text { Gene } \\
\text { symbol }\end{array}$ & $\begin{array}{l}\text { Accession } \\
\text { number }\end{array}$ & $\begin{array}{l}\text { Differential gene } \\
\text { expression log } \\
\text { base } 2\end{array}$ \\
\hline \multicolumn{4}{|l|}{ Methylation—transferase activity } \\
\hline $\begin{array}{l}\text { Protein carboxyl } \\
\text { methyltransferase } 1\end{array}$ & Pcmt1 & AI841469 & 1.09 \\
\hline $\begin{array}{l}\text { Isoprenylcysteine } \\
\text { carboxylmethyltransferase }\end{array}$ & Icmt & AI840164 & 1.84 \\
\hline Contactin 1 & Cntn1 & AI841238 & 1.48 \\
\hline 6720458f09RIK & EST & AI836341 & 1.58 \\
\hline \multicolumn{4}{|c|}{ Ras GTPase/GTP binding \& regulation } \\
\hline $\begin{array}{l}\text { Williams Beuren } \\
\text { syndrome chromosome } \\
\text { region } 16\end{array}$ & Wbscr16 & AI838628 & 1.55 \\
\hline $\begin{array}{l}\text { Kinesin-associated protein } \\
3\end{array}$ & Kifap3 & AI846587 & 1.13 \\
\hline $\begin{array}{l}\text { Ras-associated protein } \\
\text { Rab1 }\end{array}$ & Rab1 & AI836075 & 1.67 \\
\hline $\begin{array}{l}\text { Ras-associated protein } \\
\text { Rab2 }\end{array}$ & Rab2 & AI836817 & 1.63 \\
\hline $\begin{array}{l}\text { Ras homolog gene family, } \\
\text { member G }\end{array}$ & Arhg & AI834967 & -1.29 \\
\hline Ras and Rab interactor 2 & $\operatorname{Rin} 2$ & AI835968 & 1.64 \\
\hline $\begin{array}{l}\text { Ras association } \\
\text { (RALGDS/AF-6) } \\
\text { domain family } 3\end{array}$ & Rassf3 & AI839168 & 1.00 \\
\hline $\begin{array}{l}\text { Regulator of } \mathrm{G} \text { protein } \\
\text { signaling } 5\end{array}$ & Rgs5 & AI847151 & -1.51 \\
\hline \multicolumn{4}{|l|}{ Cell death } \\
\hline $\begin{array}{l}\text { WW domain-containing } \\
\text { oxidoreductase }\end{array}$ & Wwox & AI847565 & 1.13 \\
\hline $\begin{array}{l}\text { CD40 ligand-activated } \\
\text { specific transcript } 3\end{array}$ & $\begin{array}{l}\text { Clast3- } \\
\text { pending }\end{array}$ & AI843736 & 1.08 \\
\hline $\begin{array}{l}\text { Eukaryotic translation } \\
\text { initiation factor } \\
\text { 4-gamma, } 2\end{array}$ & Eif4g2 & AI836099 & -1.01 \\
\hline $\begin{array}{l}\text { Apoptosis-associated } \\
\text { tyrosine kinase }\end{array}$ & Aatk & AI837050 & -2.48 \\
\hline
\end{tabular}


Table 1 continued

\begin{tabular}{|c|c|c|c|}
\hline $\begin{array}{l}\text { Biological function } \\
\text { Gene name }\end{array}$ & $\begin{array}{l}\text { Gene } \\
\text { symbol }\end{array}$ & $\begin{array}{l}\text { Accession } \\
\text { number }\end{array}$ & $\begin{array}{l}\text { Differential gene } \\
\text { expression log } \\
\text { base } 2\end{array}$ \\
\hline $\begin{array}{l}\text { Tumor necrosis factor } \\
\text { receptor superfamily, } \\
\text { member 19-like }\end{array}$ & Tnfrsf19 1 & AI847877 & -1.03 \\
\hline Cullin 3 & $\mathrm{Cul} 3$ & AI840051 & -1.66 \\
\hline Ribosomal protein S3 & Rps3 & AI835909 & 1.11 \\
\hline Stam binding protein & Stambp & AI843579 & -1.60 \\
\hline Peroxiredoxin 2 & $\operatorname{Prdx} 2$ & AI840113 & -1.49 \\
\hline $\begin{array}{l}\text { Amyloid beta } \mathrm{A} 4 \text { precursor } \\
\text { protein }\end{array}$ & App & AI843768 & 1.02 \\
\hline \multicolumn{4}{|l|}{ Cell proliferation } \\
\hline Cyclin I & Ccni & AI836101 & 1.06 \\
\hline Adenylate kinase 1 & Ak1 & AI843939 & -2.38 \\
\hline $\begin{array}{l}\text { Eukaryotic translation } \\
\text { initiation factor 4-gamma, } \\
2\end{array}$ & Eif4g2 & AI836099 & -1.01 \\
\hline $\begin{array}{l}\text { GDP dissociation inhibitor } \\
1\end{array}$ & Gdil & AI836651 & -1.09 \\
\hline Cullin 3 & $\mathrm{Cul} 3$ & AI840051 & -1.66 \\
\hline $\begin{array}{l}\text { Sjogren syndrome/ } \\
\text { scleroderma autoantigen } 1\end{array}$ & Ssscal & AI836470 & -1.13 \\
\hline $\begin{array}{l}\text { Transforming growth } \\
\text { factor, beta-2 }\end{array}$ & $\operatorname{Tgfb} 2 *$ & AI843541 & -1.25 \\
\hline $\begin{array}{l}\text { Cd40 ligand-activated } \\
\text { specific transcript } 3\end{array}$ & $\begin{array}{l}\text { Clast3- } \\
\text { pending }\end{array}$ & AI843736 & 1.08 \\
\hline $\begin{array}{l}\text { Thyroid hormone receptor, } \\
\text { alpha-1 }\end{array}$ & Thra & AI841022 & 1.23 \\
\hline Peroxiredoxin 2 & $\operatorname{Prdx} 2$ & AI840113 & -1.49 \\
\hline Cyclin D3 & Cend 3 & AI841379 & -1.44 \\
\hline $\begin{array}{l}\text { Platelet-derived growth } \\
\text { factor receptor, alpha }\end{array}$ & Pdgfra* & AI840738 & 1.35 \\
\hline $\begin{array}{l}\text { Target of MYB1, chicken, } \\
\text { homolog of; TOM1 }\end{array}$ & Tom 1 & AI840048 & 1.26 \\
\hline $\begin{array}{l}\text { Ras homolog gene family, } \\
\text { member G }\end{array}$ & Arhg & AI834967 & -1.29 \\
\hline \multicolumn{4}{|l|}{ Kinases } \\
\hline Adenylate kinase 1 & Ak1 & AI843939 & -2.38 \\
\hline $\begin{array}{l}\text { Apoptosis-associated } \\
\text { tyrosine kinase }\end{array}$ & Aatk & AI837050 & -2.48 \\
\hline P21-activated kinase 3 & Pak3 & AI845925 & 1.10 \\
\hline $\begin{array}{l}\text { Platelet-derived growth } \\
\text { factor receptor, alpha }\end{array}$ & Pdgfra* & AI840738 & 1.35 \\
\hline $\begin{array}{l}\text { Eukaryotic translation } \\
\text { initiation factor } 2 \text { alpha } \\
\text { kinase } 1 / \text { heme-regulated } \\
\text { EIF2 alpha kinase }\end{array}$ & $\begin{array}{l}\text { Eif2ak1/ } \\
\text { Hri }\end{array}$ & AI839567 & -1.26 \\
\hline CDC-like kinase 3 & Clk3 & AI841572 & -1.48 \\
\hline Cyclin I & Ccni & AI836101 & 1.06 \\
\hline Guanylate kinase 1 & Guk1 & AI839520 & -1.19 \\
\hline $\begin{array}{l}\text { Neurotrophic tyrosine } \\
\text { kinase, receptor, type } 2\end{array}$ & Ntrk2 & AI843376 & -1.12 \\
\hline Cyclin D3 & Cend 3 & AI841379 & -1.44 \\
\hline \multicolumn{4}{|l|}{ Organogenesis } \\
\hline Peroxiredoxin 1 & $\operatorname{Prdx} 1$ & AI847967 & -1.76 \\
\hline
\end{tabular}

Table 1 continued

\begin{tabular}{|c|c|c|c|}
\hline $\begin{array}{l}\text { Biological function } \\
\text { Gene name }\end{array}$ & $\begin{array}{l}\text { Gene } \\
\text { symbol }\end{array}$ & $\begin{array}{l}\text { Accession } \\
\text { number }\end{array}$ & $\begin{array}{l}\text { Differential gene } \\
\text { expression log } \\
\text { base } 2\end{array}$ \\
\hline $\begin{array}{l}\text { Dihydropyrimidinase- } \\
\text { like } 2\end{array}$ & Dpysl2 & AI845631 & -1.16 \\
\hline $\begin{array}{l}\text { Transforming growth } \\
\text { factor, beta-2 }\end{array}$ & $\operatorname{Tgfb} 2 *$ & AI843541 & -1.25 \\
\hline $\begin{array}{l}\text { Platelet-derived growth } \\
\text { factor receptor, alpha }\end{array}$ & Pdgfra* & AI840738 & 1.35 \\
\hline Quaking & Qk & AI837287 & 1.30 \\
\hline $\begin{array}{l}\text { Oligodendrocyte lineage } \\
\text { transcription factor } 1\end{array}$ & Olig1 & AI836478 & -1.90 \\
\hline Tropomodulin 2 & Tmod2 & AI846696 & 1.04 \\
\hline Adducin 3 & Add3 & AI839335 & -1.63 \\
\hline $\begin{array}{l}\text { Thyroid hormone } \\
\text { receptor, alpha-1 }\end{array}$ & Thra & AI841022 & 1.23 \\
\hline $\begin{array}{l}\text { Ubiquitin fusion } \\
\text { degradation 1-like }\end{array}$ & Ufd1l & AI837222 & 1.19 \\
\hline Proteolipid protein 1 & Plp & AI843834 & -2.59 \\
\hline $\begin{array}{l}\text { Fibroblast growth factor } \\
12\end{array}$ & Fgf $12 *$ & AI847382 & -1.42 \\
\hline Amphiphysin I & Amph & AI837709 & -1.63 \\
\hline $\begin{array}{l}\text { Neurotrophic tyrosine } \\
\text { kinase, receptor, type } 2\end{array}$ & Ntrk2 & AI843376 & -1.12 \\
\hline \multicolumn{4}{|l|}{ Actin cytoskeleton } \\
\hline Amphiphysin I & Amph & AI837709 & -1.63 \\
\hline Tropomodulin 2 & Tmod2 & AI846696 & 1.04 \\
\hline $\begin{array}{l}\text { Erythrocyte protein band } \\
4.9\end{array}$ & Epb4.9 & AI835123 & -2.29 \\
\hline $\begin{array}{l}\text { Myosin VIIa and Rab } \\
\text { interacting protein }\end{array}$ & Myrip & AI845521 & -1.06 \\
\hline Actin-related protein 6 & $\begin{array}{l}\text { Actr6- } \\
\text { pending }\end{array}$ & AI835436 & 1.80 \\
\hline $\begin{array}{l}\text { Myristoylated } \\
\text { alanine-rich protein } \\
\text { kinase C substrate }\end{array}$ & Marcks* & AI836468 & 1.22 \\
\hline $\begin{array}{l}\text { Wiskott-aldrich } \\
\text { syndrome protein } \\
\text { family, member } 1\end{array}$ & Wasf1 & AI838537 & -1.78 \\
\hline 9930104h07RIK & EST & AI840122 & 1.91 \\
\hline Tropomodulin 2 & Tmod2 & AI846696 & 1.04 \\
\hline \multicolumn{4}{|c|}{ Growth factor/cytokine activity \& growth factor binding activity } \\
\hline $\begin{array}{l}\text { Fibroblast growth factor } \\
12\end{array}$ & Fgf12* & AI847382 & -1.42 \\
\hline $\begin{array}{l}\text { Transforming growth } \\
\text { factor, beta-2 }\end{array}$ & $\operatorname{Tgfb} 2 *$ & AI843541 & -1.25 \\
\hline $\begin{array}{l}\text { Insulin-like growth factor- } \\
\text { binding protein } 5\end{array}$ & IgFbp5 & AI843940 & -1.07 \\
\hline \multicolumn{4}{|c|}{ Transcription factor activity \& transcription factor binding activity } \\
\hline $\begin{array}{l}\text { Proteasome } 26 \mathrm{~S} \text { subunit, } \\
\text { non-ATPase, } 10\end{array}$ & Psmd10 & AI847977 & -1.75 \\
\hline $\begin{array}{l}\text { Pterin-4-alpha- } \\
\text { carbinolamine dehydratase }\end{array}$ & Pcbd & AI842101 & -1.38 \\
\hline $\begin{array}{l}\text { Oligodendrocyte lineage } \\
\text { transcription factor } 1\end{array}$ & Olig1 & AI836478 & -1.90 \\
\hline Feminization 1 homolog A & Femla & AI836048 & -1.09 \\
\hline
\end{tabular}


Table 1 continued

\begin{tabular}{|c|c|c|c|}
\hline $\begin{array}{l}\text { Biological function } \\
\text { Gene name }\end{array}$ & $\begin{array}{l}\text { Gene } \\
\text { symbol }\end{array}$ & $\begin{array}{l}\text { Accession } \\
\text { number }\end{array}$ & $\begin{array}{l}\text { Differential gene } \\
\text { expression log } \\
\text { base } 2\end{array}$ \\
\hline $\begin{array}{l}\text { Nuclear receptor- } \\
\text { interacting protein } 1\end{array}$ & Nrip1 & AI840578 & 1.32 \\
\hline $\begin{array}{l}\text { Thyroid hormone } \\
\text { receptor, alpha-1 }\end{array}$ & Thra & AI841022 & 1.23 \\
\hline $\begin{array}{l}\text { F-box and wd } 40 \text { domain } \\
\text { protein } 7\end{array}$ & Fbxw7 & AI847315 & -1.66 \\
\hline $\begin{array}{l}\text { Nuclear factor erythroid } \\
\text { 2-like } 1\end{array}$ & $\mathrm{Nfe} 211$ & AI847366 & -1.12 \\
\hline \multicolumn{4}{|c|}{ Associated members within gene families } \\
\hline $\begin{array}{l}\text { Williams Beuren } \\
\text { syndrome chromosome } \\
\text { region } 16\end{array}$ & Wbscr16 & AI838628 & 1.55 \\
\hline $\begin{array}{l}\text { Williams Beuren } \\
\text { syndrome } \\
\text { chromosome region } 21\end{array}$ & Wbscr21 & AI843349 & 1.38 \\
\hline $\begin{array}{l}\text { Transmembrane protein } \\
\text { with EGF-like and } 2 \\
\text { follistatin-like domains } 1\end{array}$ & Tmeff1 & AI842540 & 1.24 \\
\hline $\begin{array}{l}\text { Transmembrane protein } \\
\text { with EGF-like and } 2 \\
\text { follistatin-like domains } 2\end{array}$ & Tmeff 2 & AI842764 & 1.11 \\
\hline $\begin{array}{l}\text { Solute carrier family } 1 \\
\text { (glial high affinity } \\
\text { glutamate transporter), } \\
\text { member } 2\end{array}$ & Slc1a2 & AI840686 & -1.01 \\
\hline $\begin{array}{l}\text { Solute carrier family } 1 \\
\text { (glial high affinity } \\
\text { glutamate transporter), } \\
\text { member } 2\end{array}$ & Slc21a5 & AI843160 & 1.08 \\
\hline $\begin{array}{l}\text { Solute carrier family } 31 \\
\text { (copper transporter), } \\
\text { member } 1\end{array}$ & Slc31a1 & AI839005 & 1.91 \\
\hline $\begin{array}{l}\text { Solute carrier family } 4 \\
\text { (sodium bicarbonate } \\
\text { cotransporter), member } 4\end{array}$ & Slc4a4 & AI847446 & -1.02 \\
\hline Ribosomal protein S3 & Rps3 & AI835909 & 1.11 \\
\hline Ribosomal protein S25 & Rps25 & AI835709 & -1.01 \\
\hline $\begin{array}{l}\text { Ras-associated protein } \\
\text { Rab1 }\end{array}$ & Rab1 & AI836075 & 1.67 \\
\hline $\begin{array}{l}\text { Ras-associated protein } \\
\text { Rab2 }\end{array}$ & Rab2 & AI836817 & 1.63 \\
\hline Peroxiredoxin 1 & $\operatorname{Prdx} 1$ & AI847967 & -1.76 \\
\hline
\end{tabular}

Table 1 continued

\begin{tabular}{|c|c|c|c|}
\hline $\begin{array}{l}\text { Biological function } \\
\text { Gene name }\end{array}$ & $\begin{array}{l}\text { Gene } \\
\text { symbol }\end{array}$ & $\begin{array}{l}\text { Accession } \\
\text { number }\end{array}$ & $\begin{array}{l}\text { Differential gene } \\
\text { expression log } \\
\text { base } 2\end{array}$ \\
\hline Peroxiredoxin 2 & $\operatorname{Prdx} 2$ & AI840113 & -1.49 \\
\hline $\begin{array}{l}\text { Proteasome } 26 \mathrm{~S} \text { subunit, } \\
\text { non-ATPase, } 10\end{array}$ & Psmd10 & AI847977 & -1.75 \\
\hline $\begin{array}{l}\text { Proteasome (prosome, } \\
\text { macropain) 26S subunit, } \\
\text { non-ATPase, } 14\end{array}$ & Psmd14 & AI845836 & 1.02 \\
\hline $\begin{array}{l}\text { Protein kinase, interferon- } \\
\text { inducible double-stranded } \\
\text { rna-activated }\end{array}$ & Eif2ak1 & AI839567 & -1.26 \\
\hline $\begin{array}{l}\text { Eukaryotic translation } \\
\text { initiation factor 4-gamma, } \\
2\end{array}$ & Eif4g2 & AI836099 & -1.01 \\
\hline $\begin{array}{l}\text { UDP-GAL:beta-glcnac } \\
\text { beta-1,3- } \\
\text { galactosyltransferase, } \\
\text { polypeptide } 2\end{array}$ & B3galt2 & AI842276 & -1.30 \\
\hline $\begin{array}{l}\text { UDP-GAL:beta-glcnac } \\
\text { beta-1,4- } \\
\text { galactosyltransferase, } \\
\text { polypeptide } 2\end{array}$ & B4galt2 & AI846080 & 1.41 \\
\hline $\begin{array}{l}\text { ATPase, } \mathrm{Na}^{+} / \mathrm{K}^{+} \\
\text {transporting, beta-3 } \\
\text { polypeptide }\end{array}$ & Atp1b3 & AI843017 & 1.36 \\
\hline $\begin{array}{l}\text { ATP synthase, } \\
\mathrm{H}+\text { transporting, } \\
\text { mitochondrial f0 } \\
\text { complex, subunit b, } \\
\text { isoform } 1\end{array}$ & Atp5f1 & AI837594 & 1.08 \\
\hline $\begin{array}{l}\text { ADP-ribosylation factor- } \\
\text { like } 6 \text { interacting protein }\end{array}$ & Arl6ip & AI843174 & 1.08 \\
\hline $\begin{array}{l}\text { ADP-ribosylation-like } \\
\text { factor } 6 \text { interacting } \\
\text { protein } 4\end{array}$ & Arl6ip4 & AI838539 & -1.04 \\
\hline $\begin{array}{l}\text { Amyloid beta A4 } \\
\text { precursor protein }\end{array}$ & App & AI843768 & 1.02 \\
\hline $\begin{array}{l}\text { Amyloid beta precursor } \\
\text { protein-binding protein } 1\end{array}$ & Appbp1 & AI846393 & 1.09 \\
\hline $\begin{array}{l}\text { A disintegrin and } \\
\text { metalloproteinase domain } \\
17\end{array}$ & Adam 17 & AI845508 & 1.01 \\
\hline $\begin{array}{l}\text { A disintegrin and } \\
\text { metalloproteinase domain } \\
23\end{array}$ & Adam 23 & AI838132 & -1.23 \\
\hline
\end{tabular}

